\title{
Study of NASICON Structured Lithium Ion Conductor $\mathrm{Li}_{1+x} \mathrm{Al}_{\mathrm{x}} \mathrm{Zr}_{2-\mathrm{x}}\left(\mathrm{PO}_{4}\right)_{3}$
}

\author{
Xiaojuan Lu*, Xue Feng, Wenwei Lin, Haitao Liu,Yunjie Zeng \\ School of Environmental Science and Engineering, North China Electric Power University, \\ Mailbox 253, No.689 Huadian Road, Baoding, Hebei, P.R.China \\ Email: xiaojuanlv@hotmail.com
}

\begin{abstract}
Keywords: NASICON, Lithium ion conductor, Doping, Conductivity
Abstract. NASICON structured $\mathrm{Li}_{1+\mathrm{x}} \mathrm{Al}_{\mathrm{x}} \mathrm{Zr}_{2-\mathrm{x}}\left(\mathrm{PO}_{4}\right)_{3}$ have been studied to replace LAGP and LATP in this paper. The effects of both annealing temperature and Al doping were investigated. Both the annealing temperature and $\mathrm{Al}$ doping exhibited an optimal value, which is $1100^{\circ} \mathrm{C}$ and 0.3 , respectively. The doping of $\mathrm{Al}$ helped $\mathrm{LiZr}_{2}\left(\mathrm{PO}_{4}\right)_{3}$ transfer from triclinic phase to rhombohedral phase and the conductivity of doped one was improved by one order of magnitude.
\end{abstract}

\section{Introduction}

Lithium-ion batteries have been given ever increasing attention due to their high energy density, long cycle life and environment-friendly feature. Limitations of the flammable organic liquid electrolytes of the Li-ion batteries, such as safety concerns, leakage, corrosion and miniaturization difficulty, have made inorganic solid lithium ion conductors the research hotspot. Inorganic solid lithium ion conductors studied intensively include perovskite type, NASICON type, LISION type and garnet type [1].

The overall performance of NASICON structured lithium ion conductors made them possible alternatives to organic liquid electrolytes. NASICON materials have a general formula $\mathrm{Li}_{1+\mathrm{x}} \mathrm{M}^{\prime \prime}{ }_{\mathrm{x}} \mathrm{M}^{\prime}{ }_{2-\mathrm{x}}\left(\mathrm{PO}_{4}\right)_{3}$, of which $\mathrm{Li}_{1+\mathrm{x}} \mathrm{Al}_{\mathrm{x}} \mathrm{Ti}_{2-\mathrm{x}}\left(\mathrm{PO}_{4}\right)_{3}$ (LATP) and $\mathrm{Li}_{1+\mathrm{x}} \mathrm{Al}_{\mathrm{x}} \mathrm{Ge}_{2-\mathrm{x}}\left(\mathrm{PO}_{4}\right)_{3}$ (LAGP) exhibit conductivities in the range of $10^{-3}-10^{-4} \mathrm{~S} / \mathrm{cm}[2-4]$.

With its optimal ion conductive path size, the ionic conductivity of LATP system is higher than LAGP system at room temperature, but Ti4+ can be reduced to Ti3+ when in contact with lithium and thus the overall performance will be harmed. Germanium is expensive and therefore limits its applications of massive production. Zirconium, having the same valence as Ti4+ and Ge4+ and even bigger ionic radius, are stable and relatively cheap, which makes it a possibly suitable candidate to replace $\mathrm{Ti}^{4+}$ and $\mathrm{Ge}^{4+}$. Therefore, $\mathrm{Li}_{1+\mathrm{x}} \mathrm{Al}_{\mathrm{x}} \mathrm{Zr}_{2-\mathrm{x}}\left(\mathrm{PO}_{4}\right)_{3}$ system has been studied and the effects of $\mathrm{Al}$ doping and annealing temperature have been investigated in this paper.

\section{Experimental}

$\mathrm{Li}_{1+\mathrm{x}} \mathrm{Al}_{\mathrm{x}} \mathrm{Zr}_{2-\mathrm{x}}\left(\mathrm{PO}_{4}\right)_{3}$ materials with varied amounts of $\mathrm{Al}$ doping $(\mathrm{x}=0,0.1,0.2,0.3,0.4,0.5,0.6,0.7$ and 0.8 ) has been prepared by solid state reaction method in this study. Start materials used are $\mathrm{Li}_{2} \mathrm{CO}_{3}(\geq 99 \%), \mathrm{Al}(\mathrm{OH})_{3}(\geq 99 \%), \mathrm{ZrO}_{2}(\geq 99 \%)$ and $\mathrm{NH}_{4} \mathrm{H}_{2} \mathrm{PO}_{4}(\geq 99 \%)$. For each composition, stoichiometric starting materials were weighed and mixed thoroughly in a pestle mortar. Then all the mixtures were calcined at $700 \mathrm{oC}$ for 2 hours to remove volatile components and then pressed into pellets. All the pellets were sintered subsequently at $900^{\circ} \mathrm{C}, 1100^{\circ} \mathrm{C}$ and $1150^{\circ} \mathrm{C}$ for 2 hours to study effects of the doping amount of aluminum and annealing temperature.

All the sintered pellets were polished and painted with silver paste on both sides for electrochemical impedance spectra (EIS) analysis. The EIS measurements were carried out using a PARSTAT2273 station by applying an amplitude of $10 \mathrm{mV}$. The frequency range was $0.1 \mathrm{~Hz}$ to $2 \times 10^{6} \mathrm{~Hz}$.

The microstructures were examined by using an atomic force microscopy (CSPM5500). Crystallographic phases analysis was carried out by X-ray diffraction with a $\mathrm{D} / \mathrm{max}-2500 \mathrm{~J} / \mathrm{pc}$ diffractometer using a $\mathrm{Cu}$ K-radiation source $(\lambda=0.15418 \mathrm{~nm})$. 


\section{Results and Discussion}

Microstructure Examinations. All the samples have been examined by using AFM. It was found that $\mathrm{Al}$ doping has little influences on the microstructures of $\mathrm{Li}_{1+\mathrm{x}} \mathrm{Al}_{\mathrm{x}} \mathrm{Zr}_{2-\mathrm{x}}\left(\mathrm{PO}_{4}\right)_{3}$. While the microstructures of samples, despite of its $\mathrm{Al}$ amount, is strongly affected by the annealing temperature. Therefore, only AFM images of $\mathrm{Li}_{1.5} \mathrm{Al}_{0.5} \mathrm{Zr}_{1.5}\left(\mathrm{PO}_{4}\right)_{3}$ samples annealed at $900^{\circ} \mathrm{C}$, $1100^{\circ} \mathrm{C}$ and $1150^{\circ} \mathrm{C}$ are shown in Fig. 1 . The samples annealed at $900^{\circ} \mathrm{C}$ showed a powdery morphology and no well-defined grains were found on the surface, while the samples annealed at $1100^{\circ} \mathrm{C}$ started to exhibit a mixed morphology of well-defined grains and powdery regions. For the samples annealed at $1150^{\circ} \mathrm{C}$, the morphology is typical features of crystalline material with well-defined grains and grain boundaries. This is in well agreement with the theory of sintering which states thermal annealing should be able to produce the growth of contacts between particles and their coalescence.

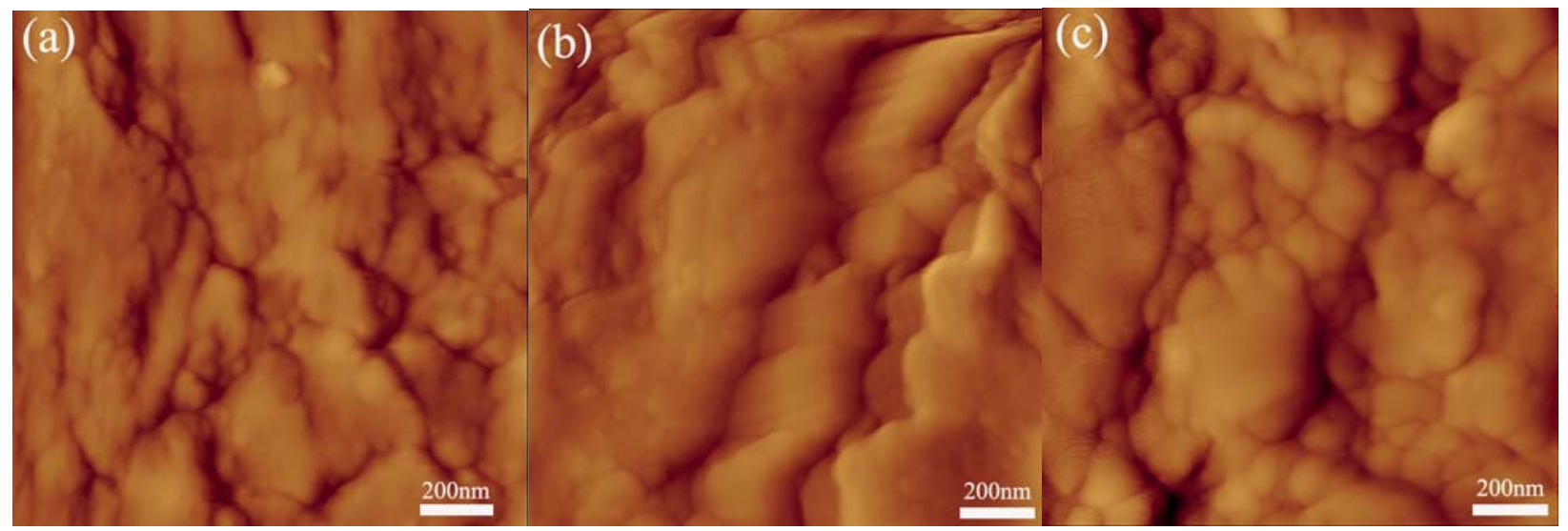

Fig. 1 AFM images of $\mathrm{Li}_{1.5} \mathrm{Al}_{0.5} \mathrm{Zr}_{1.5}\left(\mathrm{PO}_{4}\right)_{3}$ annealed at (a) $900^{\circ} \mathrm{C}$, (b) $1100^{\circ} \mathrm{C}$ and (c) $1150^{\circ} \mathrm{C}$

Electrochemical Impedance Spectra Analysis. The impedances of $\mathrm{Li}_{1+\mathrm{x}} \mathrm{Al}_{\mathrm{x}} \mathrm{Zr}_{2-\mathrm{x}}\left(\mathrm{PO}_{4}\right)_{3}$ samples annealed at $900^{\circ} \mathrm{C}, 1100^{\circ} \mathrm{C}$ and $1150^{\circ} \mathrm{C}$ have been measured by applying an amplitude of $10 \mathrm{mV}$, Nyquist plots of $\mathrm{Li}_{1.3} \mathrm{Al}_{0.3} \mathrm{Zr}_{1.7}\left(\mathrm{PO}_{4}\right)_{3}, \mathrm{Li}_{1.5} \mathrm{Al}_{0.5} \mathrm{Zr}_{1.5}\left(\mathrm{PO}_{4}\right)_{3}, \mathrm{Li}_{1.7} \mathrm{Al}_{0.7} \mathrm{Zr}_{1.3}\left(\mathrm{PO}_{4}\right)_{3}$ are shown in Fig.2-4. All the impedance spectra are shown as a semicircle followed by a tail, which are typical spectra of ionic conductors. It also can be seen from these spectra that the semicircles of the samples annealed at $900^{\circ} \mathrm{C}$ are the largest, the ones of the samples annealed at $1150^{\circ} \mathrm{C}$ rank the second and the ones at $1100^{\circ} \mathrm{C}$ are the smallest. Since all the samples have similar dimensions, the semicircles represent the conductivity qualitatively at some degree, which means the conductivities of $\mathrm{Li}_{1+\mathrm{x}} \mathrm{Al}_{\mathrm{x}} \mathrm{Zr}_{2-\mathrm{x}}\left(\mathrm{PO}_{4}\right)_{3}$ reached the maximum at $1100^{\circ} \mathrm{C}$ and then decreased slightly at $1150^{\circ} \mathrm{C}$. Therefore it can be concluded that there is an optimal annealing temperature, which is $1100^{\circ} \mathrm{C}$, for $\mathrm{Li}_{1+\mathrm{x}} \mathrm{Al}_{\mathrm{x}} \mathrm{Zr}_{2-\mathrm{x}}\left(\mathrm{PO}_{4}\right)_{3}$ samples.

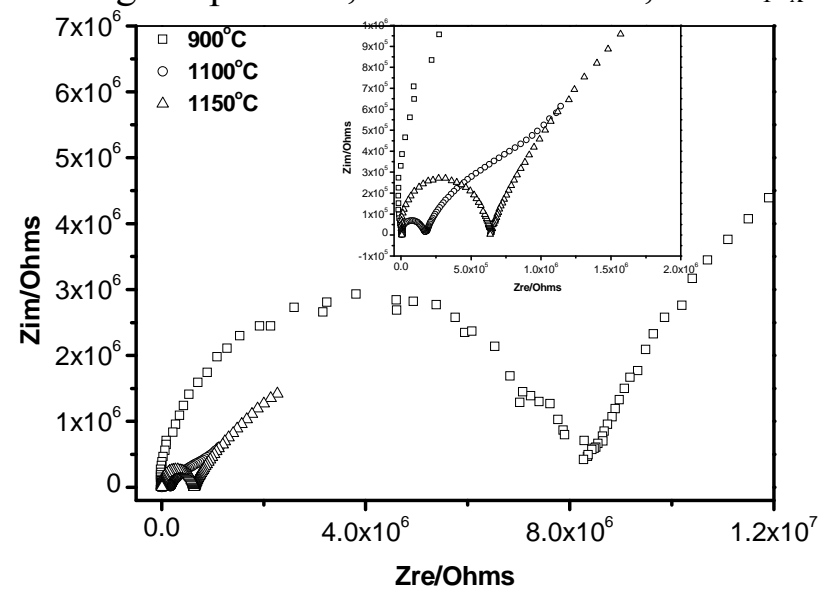

Fig.2 Nyquist plots of $\mathrm{Li}_{1.3} \mathrm{Al}_{0.3} \mathrm{Zr}_{1.7}\left(\mathrm{PO}_{4}\right)_{3}$ samples annealed at various temperatures (Inset is the enlarged part of high frequency) 


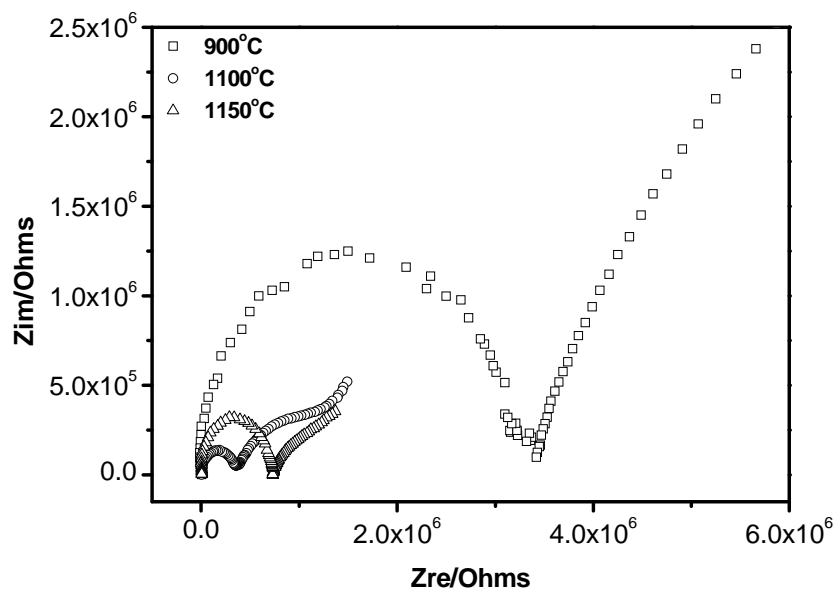

Fig.3 Nyquist plots of $\mathrm{Li}_{1.5} \mathrm{Al}_{0.5} \mathrm{Zr}_{1.5}\left(\mathrm{PO}_{4}\right)_{3}$ samples annealed at various temperatures

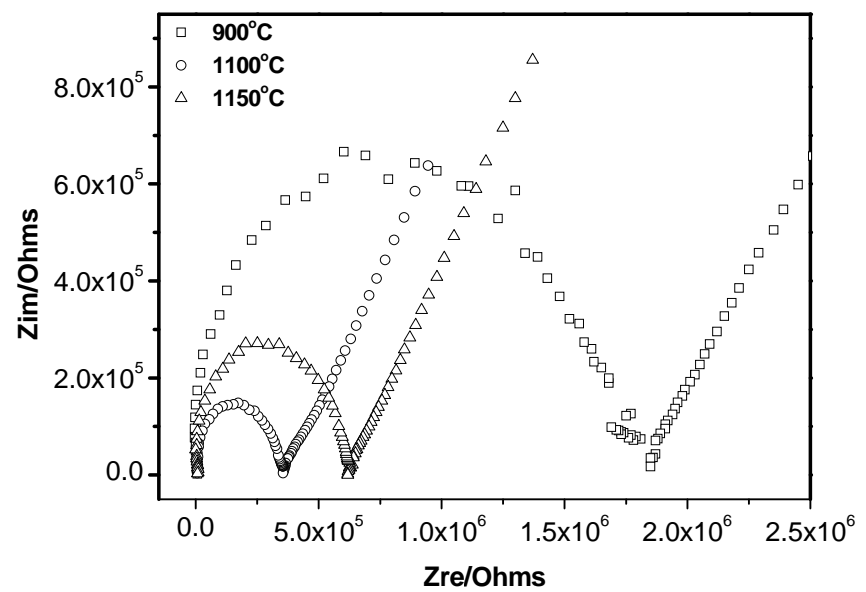

Fig.4 Nyquist plots of $\mathrm{Li}_{1.7} \mathrm{Al}_{0.7} \mathrm{Zr}_{1.3}\left(\mathrm{PO}_{4}\right)_{3}$ samples annealed at various temperatures

Nyquist plots of $\mathrm{Li}_{1+\mathrm{x}} \mathrm{Al}_{\mathrm{x}} \mathrm{Zr}_{2-\mathrm{x}}\left(\mathrm{PO}_{4}\right)_{3}$ samples annealed at $1100^{\circ} \mathrm{C}$ are shown in Fig.5. The impedance of all the samples doped with $\mathrm{Al}$ decreased compared to the ones without $\mathrm{Al}$ doping. It means $\mathrm{Al}$ dopant helped to increase the conductivities of $\mathrm{Li}_{1+\mathrm{x}} \mathrm{Al}_{\mathrm{x}} \mathrm{Zr}_{2-\mathrm{x}}\left(\mathrm{PO}_{4}\right)_{3}$ possibly by introducing extra $\mathrm{Li}^{+}$in the system. While the decreasing of impedance did not show a linear trend with $\mathrm{Al}$ doping amount, it reached the lowest when $\mathrm{x}=0.3$. Since it is difficult to distinct grain response from grain boundary response in Nyquist plots, overall ionic conductivities were calculated using Eq.1 as follows.

$$
\sigma=\frac{1}{R} \times \frac{\mathrm{h}}{S}
$$

where $\sigma$ is conductivity in $\mathrm{S} / \mathrm{cm} ; \mathrm{h}$ is the thickness of the pellet in $\mathrm{cm} ; \mathrm{S}$ is the electrode area in $\mathrm{cm}^{2} ; \mathrm{R}$ is the impedances measured in $\Omega$. According to Eq. 1, the overall conductivity of $\mathrm{Li}_{1.3} \mathrm{Al}_{0.3} \mathrm{Zr}_{1.7}\left(\mathrm{PO}_{4}\right)_{3}$ is $1.6 \times 10^{-6} \mathrm{~S} / \mathrm{cm}$ and the overall conductivity of $\mathrm{LiZr}_{2}\left(\mathrm{PO}_{4}\right)_{3}$ is $1.97 \times 10^{-7} \mathrm{~S} / \mathrm{cm}$. The conductivity is improved almost by one order of magnitude when doped with Al. XRD patterns show that crystallographic phase of $\mathrm{LiZr}_{2}\left(\mathrm{PO}_{4}\right)_{3}$ is triclinic while the samples doped with $\mathrm{Al}$ is rhombohedral. Therefore the conductivity measurement is in agreement with the fact that the triclinic phase shows a lower conductivity than the rhombohedral [5-7]. 


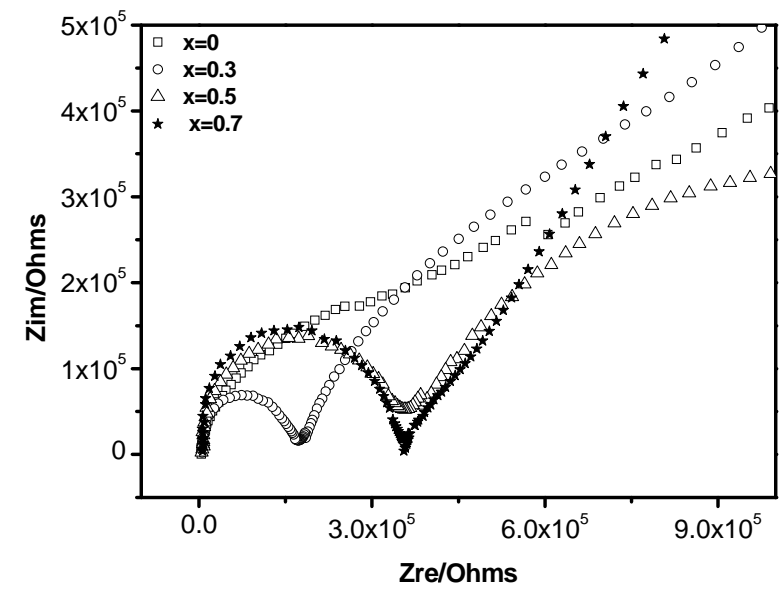

Fig.5 Nyquist plots of $\mathrm{Li}_{1+\mathrm{x}} \mathrm{Al}_{\mathrm{x}} \mathrm{Zr}_{2-\mathrm{x}}\left(\mathrm{PO}_{4}\right)_{3}$ samples annealed at $1100^{\circ} \mathrm{C}$

\section{Conclusions}

NASICON structured lithium ion conductor $\mathrm{Li}_{1+x} \mathrm{Al}_{\mathrm{x}} \mathrm{Zr}_{2-\mathrm{x}}\left(\mathrm{PO}_{4}\right)_{3}$ has been studied in this paper. The effects of annealing temperature and the doping of Al were investigated. It was found that there is an optimal value for both annealing temperature and $\mathrm{Al}$ doping. For the same amount of $\mathrm{Al}$ doping, the conductivity reached the maximum at $1100^{\circ} \mathrm{C}$. The conductivities of $\mathrm{Li}_{1+\mathrm{x}} \mathrm{Al}_{\mathrm{x}} \mathrm{Zr}_{2-\mathrm{x}}\left(\mathrm{PO}_{4}\right)_{3}$ system studied achieved the highest of $1.6 \times 10^{-6} \mathrm{~S} / \mathrm{cm}$, which is one order of magnitude higher than that of undoped ones. XRD examinations showed that $\mathrm{Al}$ doping helped $\mathrm{LiZr}_{2}\left(\mathrm{PO}_{4}\right)_{3}$ transfer from triclinic phase to rhombohedral phase.

\section{Acknowledgements}

This research was financially supported by the Natural Science Foundation of Hebei Province, China (No.E2013502272), the fundamental research funds for the central universities (No. 2015ZD25) and the Scientific Research Foundation for the Returned Overseas Chinese Scholars, State Education Ministry.

\section{References}

[1] P. Knauth: Solid state Ionics Vol. 180 (2009) , p.911.

[2] M. Zhang, Z. Huang, J.f. Cheng, O. Yamamoto, N. Imanishi, B. Chi, J. Pu, J. Li: J. Alloys. Comp. Vol. 590 (2014), p.147.

[3] H. Aono, E. Sugimoto, Y. Sadaoka, N. Imanaka, G. Adachi: J. Electrochem. Soc. Vol. 137 (1990), p.1023.

[4] J.L. Narváez-Semanate, A.C.M. Rodrigues: Solid state Ionics Vol. 181 (2010), p.1197.

[5] H. El-Shinawi, C. Greaves, J. Janek: RSC adv. Vol. 5 (2015), p. 17054.

[6] M. Catti, S. Stramare, R. Ibberson: Solid State Ionics Vol. 123 (1999), p.173.

[7] M. Catti, S. Stramare: Solid State Ionics Vol.136-137 (2000), p.489. 